\title{
Trends in e-Learning: Impacts of Social Mobile Technologies on Information Behavior, Formal Learning and the Educational Market
}

\author{
Joachim Griesbaum
}

\begin{abstract}
Social and mobile technologies are catalysts for significant changes in e-learning. Their effects develop during the process of the diffusion and adaption of these technologies on different social levels: individual (micro level), organizational (meso level) and markets/society (macro level). This paper reports on the impacts of social and mobile technologies on learning related individual information behavior, formal teaching scenarios and the educational market as a whole. Thus, the reader obtains a holistic picture of technology based influences on learning.
\end{abstract}

Index Terms-Social and mobile technologies, information behavior, formal learning, educational market.

\section{INTRODUCTION}

Technology usage is one of the basic determinants in the way we learn. In fact, the term e-learning literally expresses the straight connection between technology and learning. The diffusion of mobile and social technologies can be seen as a catalyst for current trends in e-learning. These technologies allow for widely unrestricted information access and socially unlimited communication. In addition, learning is no longer constrained by limited time and space. Looi et al. [1] speak of "seamless learning spaces" that smoothly switch between formal and informal and between individual and social learning. Trends like employing tablets in classrooms, MOOCs (Massive Open Online Courses) etc. can all be connected to the diffusion of mobile and social technologies. Although there is manifold research on mobile and social learning, scientific investigations are often focused on in the design and outcomes of specific case studies. Studies and theoretical analysis that aim for a more comprehensive perspective are comparatively rare.

This is the starting point of this work. The paper aims to outline impacts of social and mobile technologies on learning. It reports on the impacts of social and mobile technologies on learning related individual information behavior (micro level) formal teaching scenarios (meso level) and the educational market (macro level). By integrating such different perspectives, the reader gets an encompassing classification of current development which mentions short term gains but also introduces long-term implications. One should keep in mind that the article here only claims to be a rough tentative draft. The goal is to foster the ongoing discussion in the field,

Manuscript received September 9, 2015; revised November 25, 2015.

Joachim Griesbaum is with the Department of Information Science and Natural Language Processing, University of Hildesheim, Hildesheim, Germany (e-mail: joachim.griesbaum@uni-hildesheim.de). and not to provide answers.

The paper is structured as follows. First, there is a short introduction in trends in e-learning and the diffusion of mobile and social technologies. Following that, some important trends on learning about related individual information behavior are laid out. Then, developments on the educational market as a whole are touched on. The paper closes with a discussion of changes of the educational ecosystem and its consequences.

\section{TeChNOLOGICAL Change AND CURRENT TRENDS IN E-LEARNING}

E-learning is nothing new; it has been established as a scientific discipline and as an infrastructure (at least in higher education) for at least 10 years [2]. Nevertheless, the emergence of smartphones and the large success of MOOCS affect individual information behavior as well as the educational landscape. Smartphones are mobile and user friendly computers that allow continuous usage. Thus, everyone can access information and communicate with ease and everywhere. Reference [3] executed a survey in four different countries on mobile device usage "in life and learning." The authors state, "the most prominent uses are contact with others, immediate access to information and answers, reading e-books, listening to podcasts, and scheduling." Thus, mobile devices are personal learning tools with manifold applications. Especially tablets show the potential to transform the classroom, alleviating information management and fostering group work and collaboration. Finally, there is the (ongoing) discussion on MOOCs. According to [4]: "Nothing has more potential to unlock a billion more brains to solve the world's biggest problems. And nothing has more potential to enable us to reimagine higher education than the massive open online course, or MOOC, platforms..." In compliance with that, one can even imagine that there will be a time when we no longer rely on or even need real physical classrooms. Theoretically, education can happen widely online.

As one can see, there are many different impacts of mobile and social technologies on learning.

None of the above mentioned trends are predetermined or set by the technology itself. Technological change is a social process which passes through different stages. The invention of a technology can be seen as an enabler, a catalyst for technological change. According to [5], the (delayed) diffusion of a technology is dependent on the perceived advantages and resulting adoption decision of innovators and 
the communication of its advantages amongst them and through mass media. Not every technology is successful, e.g. video phones and cargo lifter technologies are not widely adopted yet. As mobile and social technologies are network goods (which means their benefits are dependent on the usage of others), their dissemination is dependent on the adoption decisions of other users. Once a critical mass is reached, the penetration accelerates. Current social and mobile technologies can be assessed as showing high technology acceptance and strong network effects. Therefore their adoption was very successful and very fast.

Hart and Hart Frejd [6] even speak of a "digital invasion," which first happens subtly but with inevitable consequences. The effects of technology change depend on the users which adapt existing behavioral patterns according to the possibilities provided by the technology and develop new behavioral patterns enabled by the technology. Over time, organizations adapt too. They adjust processes and develop new products. Finally (and "slowly"), one can observe social changes or transformation of markets (Fig. 1).

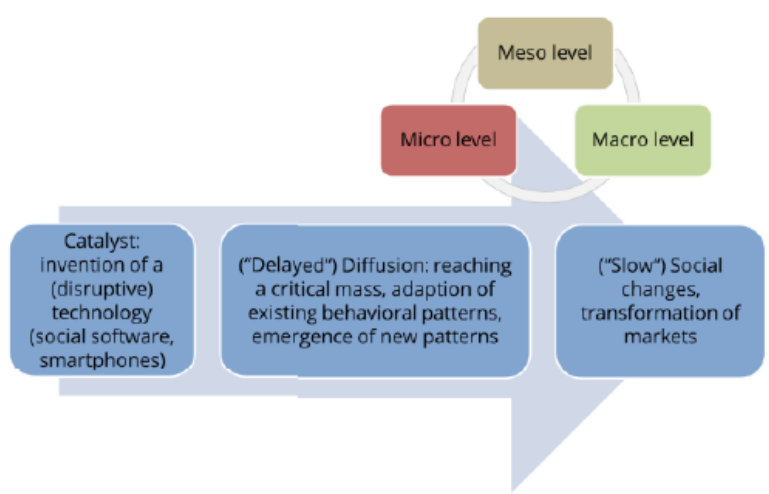

Fig. 1. Technological change as a social process.

The process is never finished as new inventions are steadily made. In the case of learning and technology, ubiquitous computing and the sensor web [7] could be the new game in town.

This is the context in which the following explanations should be categorized. These should be seen as a snapshot on a background in which mobile and social technologies are widely adapted on a micro and partly on a meso level. Seen from the macro level perspective or rather long term related behavioral changes on micro and meso levels, the diffusion has probably only just begun. In the following we will discuss currently visible impacts of this technological change with regard to learning related individual information behavior, the design and outcomes of formal learning scenarios and effects on the educational market.

\section{LEARNING RELATED INFORMATION BEHAVIOR}

Concerning the impacts of mobile and social technologies on learning related information behavior, two perspectives are considered. First, advantages and dangers seen from a cognitive perspective are described. Second, ergonomics and health related aspects are delineated.

With regard to the cognitive perspective, we can continue on the argumentation of [1]. Mobile devices truly enable everybody to learn everywhere and every time. According to
[8], students especially value ubiquity and convenience of information access on mobile devices, allowing learning even through idle time and in transit. Furthermore, referring to the thesis of improved memory performance of multi-modal and multi-codal learning resources as argued by Mayer [9], one may also postulate that the possibilities of sensor based interaction and augmented reality could improve information processing. Synchronizing learning with sensor based real world interaction can provide a rich and authentic context of learning experiences, thus equally leading to a better memory performance [10]. On the other hand, users can easily become victims of distraction and interruption.

According to the Cisco Connected World Technology Report in 2011 [11], 40\% of college students get interrupted three times or more (per hour) through their mobile device when trying to focus on a project or homework assignment. Beyond that, [6] anticipate a danger of shallow learning and cognitive impoverishment as mobile device users could easily get accustomed to instant gratification and therefore show a reduced willingness (and, in the long run, capability) to endure (challenging/hard/lengthy) cognitive efforts.

Apart from these cognitive "engagement" factors, mobile devices allow for effortless information management. One can search, store, retrieve and use information everywhere and every time. But what are the cognitive effects of reading text on screens? According to [12], early studies indicate a different reading behavior on screen than on paper, resulting "in slower reading times not necessarily a lower reading comprehension." A recent study, [13], compares reading on tablet, laptop and paper investigated reading time and reading comprehension in multitasking vs. focused conditions on easy vs. difficult text passages. As a result, neither multitasking nor medium impacts reading comprehension but multitasking resulted in longer reading times over all conditions. Thus, seen from a cognitive perspective, reading on screen is not worse than reading from paper. Still most people prefer reading on paper. Why? Probably, habits and cultural preference ergonomic factors play a role.

With regard to ergonomics there is a divided picture. On the one hand, mobile devices may cause eye strain through background lighting and reflections. On the other hand, mobile devices allow for an adaptive presentation, especially useful for visually impaired and elderly people. Fig. 2 shows different possibilities to display text on a mobile device.

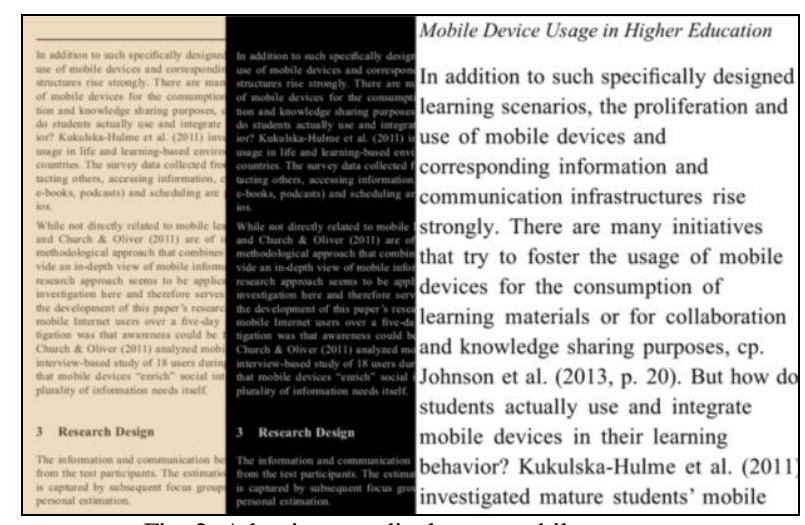

Fig. 2. Adaptive text display on mobile screens.

In continuation with ergonomics, health related effects need to be considered too. The long term health effects of 
increasing daily on-screen time are widely unexplored yet. Reference [14] investigated flexed neck and head postures through mobile device usage. Results indicate possible dangers of back injuries through prolonged device usage.

In sum, the above explanations show that mobile technologies impact learning related individual information behavior on many levels. As an interpretation, maybe the phrase "the mighty helpless learner" gets to the heart of the matter? We see the empowerment of the user through seamless learning possibilities and ubiquitous personal information management. At the same time, there are manifold opportunities for distraction and instant gratification with could lead to shallow learning. Appropriate media usage on mobile devices requires a much stronger self-guidance capacity for expedient (focused) technology usage than any other media before. Possibly, the ability to restrict media usage becomes the most important part of one's own media literacy. Finally, it becomes clear that long term effects on cognition and health are, at current, hardly explored.

\section{FORMAL LEARNING AND TEACHING SCENARIOS}

In the precedent chapter we primarily argued the implications of mobile and social learning technologies on self-directed informal learning behavior. The scope of this chapter is on impacts in formal education. Research in e-learning is usually focused on this perspective, often investigating in-class learning in specific case studies. The presentation here resembles this. It basically depicts results from some selected case studies.

But just to remember that the usage of information and communication technologies (ICT) in teaching to improve formal education scenarios is nothing new, the representation starts with "Knowledge Forum." "Knowledge Forum" was an infrastructure to realize knowledge building environments. Its roots reach back well into the 1980s [15]. It can be estimated as one of the first significant approaches of computer supported collaborative learning (CSCL). The didactic concept is based on inquiry based learning by doing research in knowledge building communities. Starting from real life problems, e.g. "causes of pollution," learners state their ideas, theses and questions and collaboratively work on learning tasks like searching relevant resources. In this process of knowledge building they expand their common knowledge and reflect and discuss on that. If one is reminded about the "modern" concept of connectivism, that should be no surprise; such approaches are related and very similar. Connectivism stresses the value of networks and connections of and to learning resources and states that "learning and knowledge rests in diversity of opinions" [16]. The postulates of connectivism can be easily related to approaches of cooperative learning which are well established in CSCL, cp. [17]. Therefore, it should be noted that the idea of using social technology to enhance teaching by connecting learners in new digital ways is nothing "new." Hence, the emphasis on the following case studies is on mobile technologies. New applications of social technologies that allow for educational offers which are socially unlimited (MOOCs) are discussed in the next chapter.
In 2010, the Department of Education and Early Childhood Development (Australia) undertook a large scale trial of introducing 660 iPads in 10 primary, secondary and special schools [18]. The results of the evaluation of tablet usage in class and at home were very encouraging. In different surveys the estimations of 457 pupils, 172 parents and 101 teachers were collected. As a whole, data indicates a shift to learner-centered and collaborative teaching.

Reference [19] investigated iPads as a literacy teaching tool in early childhood. They introduced iPads in two preschool classrooms of four and five year-old children. The study was conducted over a seven week period. Every two weeks, new apps were additionally installed. Apps were chosen by the researchers. The teachers, who were not familiar with the iPads, decided on the use of the tablets and apps. During the first two weeks, writing and speaking apps were provided. In the third week, apps encouraging listening and print awareness were chosen. In the last three weeks, further writing, speaking and listening apps were installed. Data collection encompassed twice weekly observations, the analysis of digital work samples and parent emails, an informal survey of parents and interviews with the teachers. Results were very positive. Apart from intensified interaction with each other, children were creative, drew images, used the keyboard and watched other children using the device giving hints on usage. The authors conclude that the children acquired first literacy abilities for self-expressing. The authors state: "[...] both teachers suggested that the communication between children [...] was the biggest difference [...]. Mrs. Timmons noted that, even when working individually $[\ldots]$, children would still engage in meaningful conversations with the children around them..."

Another study tested a game and inquiry based teaching approach with smartphones [20]. Fourth- and fifth-grade students in an elementary classroom used a phone app to create single choice questions. These questions then had to be solved and rated by their peers. The post survey showed that the scenario was highly accepted by the students. They especially assessed the questions of their peers as good for review.

Furthermore, [21] compared group work with/without a tablet in a 9th grade physics lesson in a comprehensive school. In two classes of 28 each, pupils had to document and analyze an experiment on gravity. In small group work, pupils used either tablets or paper for documentation and analysis. Results suggest a more homogeneous learning success for the tablet groups as no learner of this condition reached less than $50 \%$ of the post test score. In addition, intensified group communication was observed and with no social loafing.

As a final example study, actually investigating device focus and device sharing, [22] realized a learning scenario which shows the potential of mobile devices to enhance teaching by enriching the context in which learning happens. The authors combine an outdoor mobile location-based game, the discovery and excavation of a notional Roman villa with indoor classroom activities for primary school children. GPS-enabled smartphones formed the core of mock-up tools to fake real excavation tools like metal detectors, which were then used to discover and excavate virtual objects. According to the authors, the students were highly motivated. 
In sum, this short sketch on current research illustrates possible advantages of mobile technologies in formal learning. There is a potential for positive motivational effects, intensified interaction and self-directed learning in authentic learning scenarios. Maybe, some of these advantages are rather a result of a novelty effect than being "real." Furthermore, we also can easily see the outcomes are depending on the configuration of the whole learning scenario. Technology is only a part of the learning environment; didactics and content play a decisive role. Thus, the teacher remains the central stakeholder to ensure and foster the quality of formal education. It is his/her task to initiate and control learning designs which are able to realize the potentials of mobile and social technologies for learning.

In sum, as the few mentioned studies illustrate, current research comes to a rather positive view of the educational value of mobile devices in formal learning and teaching scenarios. Unfortunately, the dangers of "appucation" are barely mentioned in the scientific literature. At current, there is an emerging market and already a broad range of learning apps available for computers and mobile devices. Such learning apps often provide exercises, tutorials or simulations with regard to specific learning related topics, e.g. vocabulary and arithmetic exercises, simulations to learn to play the piano etc. At first sight, such learning apps often correspond to important requirements of "modern" didactics, e.g. they are often adaptive and game-based. Nevertheless, relying on the argumentation of Kohn who writes about "Four Reasons to Worry About 'Personalized Learning"' [23], such adaptive and game-based learning apps rather reflect a personalized and pre-determined "drill and practice" knowledge transmission scheme instead of an approach of self-directed construction of meaning. That means the usage of such tools in formal education can be connected to a revival of "old fashioned" instructional practices. Seen from this point of view, one could ask if the diffusion of mobile technology involves a tendency to "dehumanize learning" too. The last remark should be interpreted as a critical side remark. Apps can also be used for creative learning, as we have seen in the previous case studies.

\section{EDUCATIONAL MARKET}

What's the impact of mobile and social technologies on the macro level? As argued in the preceding chapter, there is a developing market of learning apps, primarily emerging in the Android and iOS app stores and focusing on mobile devices. The reason and background of this development is a significant change with regard to the educational market as a whole, as new types of services and content providers arise.

Educational publishers, who traditionally provided paper based schoolbooks as primary learning resources for the school system, are coming under increasing pressure to adapt. Learning resources are more and more provided as digital resources or are enhanced with digital offers.

In addition to this trend of digitalization of learning resources, there is a growing demand for implementation services as well. A use case is the introduction of tablets into formal education. For example, Insight (www.ips.insight.com), a typical ICT service provider, also offers "infrastructure" and "personal learning devices" services for schools. Another example is the schoolTab team of Madsack, a media group offering implementation support (hardware, software and training) for tablet classes. That means there is a demand on manifold new kinds of services and new types of players are emerging and entering the educational market. This additional technical layer brings a new dimension of complexity in education. Many questions are still widely unanswered. For schools, topics like licensing models, data protection and copyright are not trivial. Even the question of how to allocate the necessary resources and competencies for this kind of digitalized education is challenging and often unclear. The digitalization of the formal education system is just at the beginning (at least in Germany). Nonetheless, the diffusion of mobile technologies leads to an increasing need and demand for organizational information management, a challenge and chance for educational institutions and also service and content providers.

With regard to the latter, there are also new types of educational resources. Open Educational Resources (OER), which are openly available for everyone and usually at no cost, were first provided in the context of higher education. MIT OpenCourseWare (http://ocw.mit.edu), providing free learning materials of higher education courses, can be seen as one of the pioneers in the OER movement. The fuse school (a charity branch of www.fuseuniversal.com, a e-learning company), as another example, aims to create a library of 4,000 open educational videos for school education. The following figure shows a picture of one of the videos.

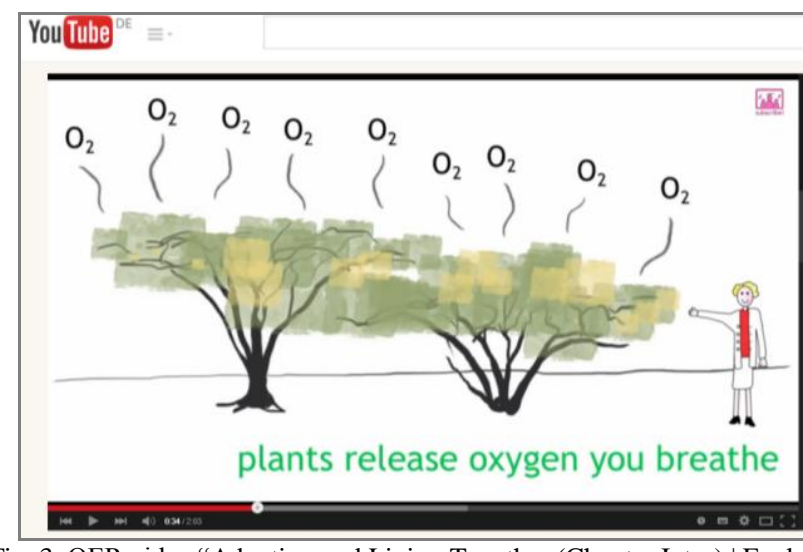

Fig. 3. OER video "Adapting and Living Together (Chapter Intro) $\mid$ Ecology and Environment | The Virtual School," https://www.youtube.com/watch?v=RwfpAltkJ50\&list=PL9262CF2DC192 E090.

Similar to the open source and open access movement in software development and scientific research, there is also an open movement or counterpart in education. OER can be seen as an alternative or supplement to commercially distributed resources. As the costs of knowledge production, distribution and collaboration diminish with the help of social software and platforms, one can expect a further expansion of this field. For example, at zum.de, the biggest German OER website, teachers provide a comprehensive collection of materials (e.g. exercises) for teaching and teacher education. At Schulbuch-O-Mat.de, one can find a collaborative production of OER type school books. In summer 2013 an e-book was finished which covers all obligatory content for biology 
classes 7 and 8 according to the official curriculum of the Bundesland Berlin.

In addition to this new type of educational resources, there are also new types of educational offers. The diffusion of MOOCs and the corresponding public and scientific discussion on the topic sparks the field of e-learning in many ways and with great impact. In August 2015, the European MOOCs Scoreboard lists 1,759 European MOOCs. MOOCs originated as learning environments that correspond to connectivist ideas of (cooperative) learning. The rising popularity and media presence of MOOCs are the result of the success and large audiences of courses offered on platforms like Edx, Udacity and Coursera, which predominately follow a docent-centric knowledge distribution metaphor [24]. The concept and diffusion of MOOCs is directly connected to the idea and the adaption of socially unlimited communication. The long term effects and impacts of this "massification" of learning are still unclear. In any case, MOOCs make it clear that education is not necessarily bound to local institutions, classes, or learner cohorts of a relatively small number of learners.

Connected to MOOCs, we also see an expansion of educational providers. With the technology easily available at possibly no or low costs, everyone can be a learning provider, theoretically. At current, we can observe that MOOCs are no longer exclusively provided by higher education but also in and by enterprises. The following Fig. 4 shows a screenshot of openSAP, the website on which the company SAP presents its MOOCs.

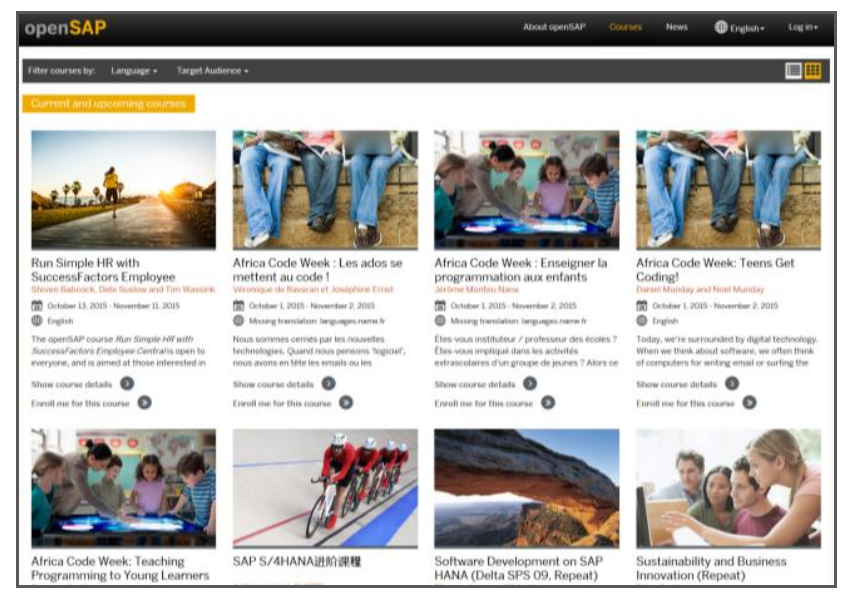

Fig. 4. MOOC-website of SAP, https://open.sap.com/courses.

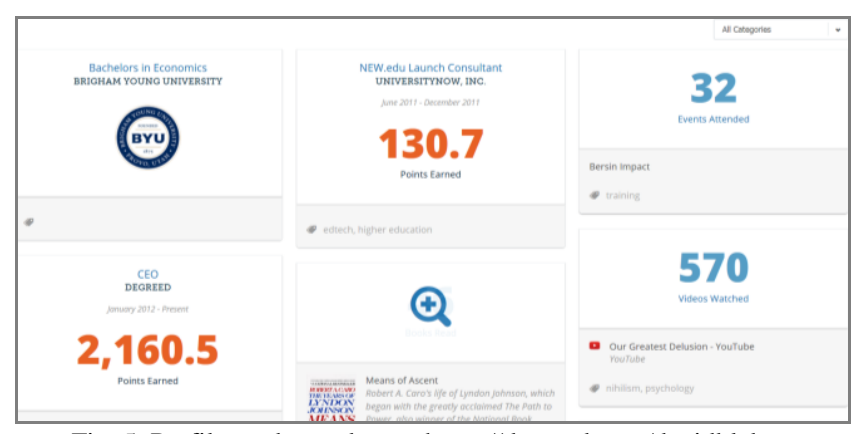

Fig. 5. Profile on degreed.com, https://degreed.com/davidblake.

As with service and content providers, we see the start of an expansion of the players in the educational market. The question of how far such educational providers are a real challenge or alternative to the public educational intuitions is partly dependent on the acceptance and reputation of their certificates.

Here, again, alternative forms and providers for certification arise. Degreed.com is a company that offers portfolios that show results of formal and informal learning on a publicly available profile. On the following figure, as one can easily see, the profile shows not only certificates acquired in formal learning but also achievements of informal learning activities. Thus, such a profile provides a "complete" picture of the competencies of the specific person.

Reference [25] argues that the importance of traditional degrees will decline as more relevant signals of peoples' capabilities, e.g. "work samples, personal representations, peer and manager reviews, shared content and scores and badges" are increasingly available and used.

In sum, as an interim conclusion of the educational market, there is a trend towards comprehensive digitalization. This digitalization trend is applicable for learning tools and infrastructure but also for learning resources. In addition, there is a significant expansion of the educational market itself. This includes the type and number of (service) providers, the type and amount of (free) resources and also educational offers and market players. Anyone can be a provider and anyone can build and publish resources. Furthermore, there is a broad tendency of commercialization. At the same time, non-profit, free and voluntary work and resources are becoming more important and significant than ever.

\section{DISCUSSION}

What is the result of this paper? The aim was to obtain a holistic picture of technology based influences on learning. Therefore, the paper reported on the impacts of social and mobile technologies on learning related individual information behavior, formal teaching scenarios and the educational market as a whole.

What can we conclude and possibly learn from this presentation? Surely, this paper is not a forecast nor does it want to be. Nevertheless, it shows important effects of the diffusing of mobile and social technologies. If we bring all three perspectives together, we can draw a picture of important trends in the educational ecosystem as a whole. In the following, we align these results on an educational value chain, seen from the learners' perspective. This unites the micro, meso and macro levels as laid out in the introduction. The value chain encompasses the information behavior of the learner, the (selection of) teaching offers, the design of teaching offers and certification. Fig. 6 shows the value chain and the impacts of mobile and social technology change in an overview.

Starting with the "mighty helpless learner," there is an empowerment of the user through seamless learning possibilities and ubiquitous personal information management. At the same time, learners are constantly lured into instant gratification and distraction. Both could lead to shallow learning. Yet, long term effects on cognition and health are rather unclear. When learners are selecting teaching offers, they can choose from a widely expanded range of market offers, firstly, with regard to resources, but also in 
relation to providers. As our presentation of case studies indicates, mobile technologies can have a very positive impact on the quality of teaching offers. With regard to MOOCs, the paper rather only scratched the surface. But one may argue here that the "massification" of learning comes at a price, a rather low level of instructional quality [26] and learning scenarios which can often barely claim to address the higher levels of learning goals.

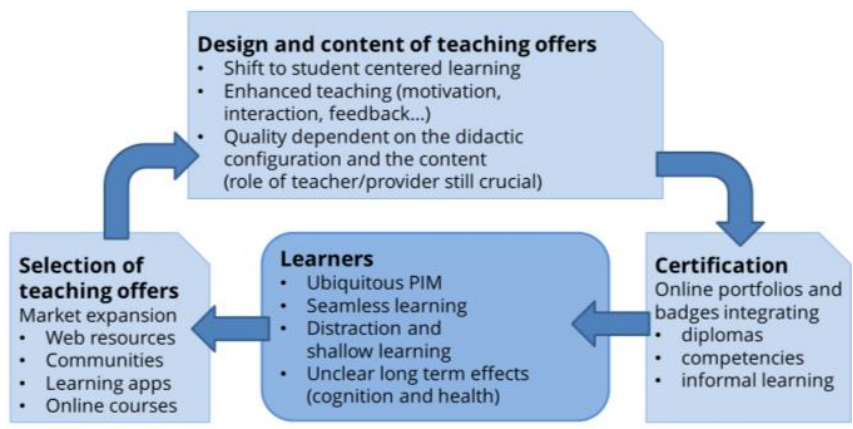

Fig. 6. Impacts of mobile and social technology diffusion on the educational value chain.

The measurement of learning success may also change to a large extent, possibly providing a much more comprehensive and detailed picture of competencies of learners than ever before. Thus, informal learning gets more extrinsic value. This could bear an influence on the selection of learning and teaching offers beforehand, which, in turn, could have an impact on educational offers provided on the market itself.

So what can we learn? On the micro level the difficult path between cognitive empowerment and impoverishment becomes visible. Learners' capacities to purposefully focus their device usages by themselves (to be able to define one's own media consumption) defines to a large extent if they are masters or victims of the technology. Thus, educational institutions should focus to teach this kind of information literacy. The primary competency is no longer the task to be able to operate technology, but rather the question of when to use it and how to set limits on device usage.

On the meso level, the deduction here is that there are indeed possible education related advantages of learning technology... if technology usage is defined "rightly." It is the task of instructors to find the right balance. Teachers cannot be replaced and human-to-human interaction should be fostered. Learning apps and MOOCs should not be used as a substitute to replace human-to-human communication with computer medicated communication and learning tools that follow a "drill and practice" paradigm, even if these offers bear the labels adaptive and game-based.

With regard to the macro level, the presentation shows new types of offers and emerging actors and a commercialization which seems to soak established structures and to diminish the role of settled (public) players. Nevertheless, existing resources (structural and human) still form the core of quality in education. One cannot expect that commercial players are obliged to fulfill the educational mission and assignments of the society. In relation to the last mentioned aspect, the OER movement provides an enormous, often widely untapped, contribution to the educational ecosystem on all three social levels (micro, meso and macro) and is therefore of high societal value.

\section{REFERENCES}

[1] C.-K. Looi, P. Seow, B. Zhang, H.-J. So, W. Chen, and L.-H. Wong, "Leveraging mobile technology for sustainable seamless learning: A research agenda," British Journal of Educational Technology, vol. 41, pp. 154-169, 2010.

[2] E. K. Kigozi, L. Ekenberg, H. Hansson, F. F. Tusubira, and M. Danielson, "Exploring the e-learning state of art," Electronic Journal of e-Learning, vol. 6, no. 2, pp. 77-88, 2008.

[3] A. Kukulska-Hulme, J. Pettit, L. Bradley, A. A. Carvalho, A. Herrington, D. M. Kennedy, and A. Walker, "Mature students using mobile devices in life and learning," International Journal of Mobile and Blended Learning (IJMBL), vol. 3, no. 1, pp. 18-52, 2011.

[4] T. L. Friedman. (January 2013). Revolution hits the universities. The New York Times. [Online]. Available: http://www.nytimes.com/2013/01/27/opinion/sunday/friedman-revolu tion-hits-the-universities.html?

[5] E. M. Rogers, Diffusion of Innovations, 4th ed., New York: Free Press, 2010.

[6] A. D. Hart and S. Hart Frejd, The Digital Invasion. How Technology Is Shaping You and Your Relationship, Grand Rapids: Baker Books, 2013.

[7] T. O’Reilly and J. Battelle. (2009). Web squared: Web 2.0 five years on. $\begin{array}{llll}\text { Web } & 2.0 & \text { Summit. } & \text { [Online]. }\end{array}$ http://www.web2summit.com/web2009/public/schedule/detail/10194

[8] M. Maifarth, J. Griesbaum, and R. Kölle, "Mobile device usage in higher education," in E-Learning Zwischen Vision und Alltag, Medien in der Wissenschaft, vol. 64, C. Bremer and D. Krömker, Eds., Münster: Waxmann, 2013, pp. 332-327.

[9] R. E. Mayer, "Multimedia learning: Are we asking the right questions?" Educational Psychologist, vol. 32, no. 1, pp. 1-19, 1997.

[10] M. Specht and M. Ebner, "Mobiles und ubiquitäres lernen Technologien und didaktisches aspekte,"Lehrbuch Für Lernen Und Lehren mit Technologie.

[11] Cisco. (2011). Cisco connected world technology report. [Online]. Available:

http://www.cisco.com/en/US/netsol/ns1120/index.html\# 2011

[12] A. Dillon, "Reading from paper versus screens: A critical review of the empirical literature," Ergonomics, vol. 35, pp. 1297-1326, 1992.

[13] K. Subrahmanyam, M. Michikyan, C. Clemmons, R. Carrillo, Y. T. Uhls, and P. M. Greenfield, "Learning from paper, learning from screens: Impact of screen reading and multitasking conditions on reading and writing among college students," International Journal of Cyber Behavior, Psychology and Learning, vol. 3, no. 4, pp. 1-27, 2013.

[14] J. G. Young, M. Trudeau, D. Odell, K. Marinelli, and J. T. Denerlein, "Touch-screen tablet user configurations and case-supported tilt affect head and neck flexion angles," Work, vol. 41, pp. 81-91, 2012.

[15] M. Scardamalia and C. Bereiter, "Knowledge-building-environments Extending the limits of the possible in education and knowledge work," in Encyclopedia of Distributed Learning, A. DiStefano, K. E. Rudestam, and R. Silverman, Eds., Thousand Oaks, CA: Sage Publications, 2003, pp. 269-272.

[16] G. Siemens. (January 2005). Connectivism: A learning theory for the digital age. International Journal of Instructional Technology and Distance Learning. [Online]. Available: http://www.itdl.org/journal/jan_05/article01.htm

[17] R. Kop and A. Hill. (October 2008). Connectivism: learning theory of the future or vestige of the past? The International Review of Research in Open and Distance Learning. [Online]. 9(3). Available: http://www.irrodl.org/index.php/irrodl/article/view/523/1103

[18] Department of Education and Early Childhood Development, iPads for Learning. In their hands trial. Evaluation Report. Sunbury. [Online]. Available:

http://api.ning.com/files/Ax7txSNuxTshTTNfez3aWOS*x9n1DYyk WZXJEybikgHuD41UjiYtouRHcp*e0cG6XR17LvkXeDWNcTnfrD QE0VtxAuWm-IHb/EDUTRACK_n839795_iPads_for_learning_In_ your_hands_trial_evaluation_report.DOC

[19] B. Beschorner and A. Hutchison, "iPads as a literacy teaching tool in early childhood," International Journal of Education in Mathematics, Science and Technology, vol. 1, no. 1, pp. 16-24, 2013.

[20] S. Seol, A. Sharp, and P. Kim, "Stanford mobile inquiry-based learning environment (SMILE): Using mobile phones to promote student inquiries in the elementary classroom," presented at the 2011 World Congress in Computer Science, Computer Engineering, and Applied Computing, 2011.

[21] A. Bresges, R. Beckmannn, J. Schmoock, A. Quast, J. Schunke-Galley, J. Weber, D. Firmenrich, R. Beckmann, and M. Kreiten, "Das 
'Reichshofer Experimentierdesign' zur Entwicklung und Überprüfung des Einsatzes von iPad oder anderen Tablet-PC im Physikunterricht," PhyDid B-Didaktik der Physik-Beiträge zur DPG-Frühjahrstagung.

[22] M. Winter and L. Pemberton, "Unearthing invisible buildings: Device focus and device sharing in a collaborative mobile learning activity," International Journal of Mobile and Blended Learning (IJMBL), vol. 3, no. 4, pp. 1-18, 2011.

[23] A. Kohn. (2014). Four reasons to worry about "personalized learning." [Online]. Available: http://www.alfiekohn.org/blogs/four-reasons-worry-personalized-lear ning/

[24] J. Blom, H. Verma, N. Li, A. Skevi, and P. Dillenbourg. (2013). MOOCs are more social than you believe. E-Learning Papers. [Online]. $33 . \quad$ Available: https://oerknowledgecloud.org/sites/oerknowledgecloud.org/files/Fro m-field_33_1.pdf
[25] M. Staton. (January 2014). The degree is doomed. Harvard Business Review. [Online].

Available: https://hbr.org/2014/01/the-degree-is-doomed

[26] A. Margaryan, M. Bianco, and A. Littlejohn, "Instructional quality of massive open online courses (MOOCs), "Computers \& Education, vol. 80, pp.77-83, 2015.

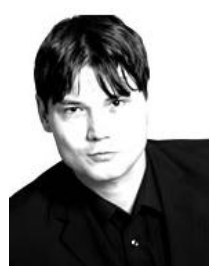

Joachim Griesbaum was born in Lahr, Schwarzwald, Germany in 1971. He obtained his doctoral degree in information science in 2006 from the University of Konstanz in Germany. In 2008 he joined the University of Hildesheim, Germany as an assistant professor of information science. His research interests include social media, e-learning, knowledge management and online marketing. 